\title{
Pharmacovigilence and the Plight of Chronic PAIN PATIENTS: IN PURSUIT OF A REALISTIC AND RESPONSIBLE ETHIC OF CARE
}

Daniel S. Goldberg* and Ben Rich ${ }^{\star *}$

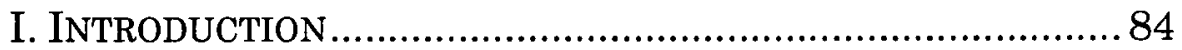

II. THe CoNvergenCE OF Two PERfECT STORMS .................. 86

III. OPIOID CONTRACTS AND THE STANDARD OF CARE FOR

CHRONIC OPIOID THERAPY ................................................ 88

IV. Competing Models of the Physician-Patient

RELATIONSHIP .......................................................... 90

V. A BRIEF History of the Use of Physician-PATIENT

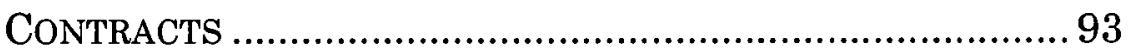

VI. INFORMED CONSENT ......................................................... 97

A. Elements of Informed Consent as They Relate to Pain Management........................................................... 98

B. Important Considerations in the Process of Informed Consent for Pain Therapy. 100

VII. OPIOID CONTRACTS IN THE MANAGEMENT OF CHRONIC PAIN. 102

VIII. The UnIVERSAL PRECAUTIONS APPROACH................... 104

IX. ADHERENCE Monitoring Through URINe DRUG SCREENING IN OPIOID THERAPY ...................................... 108

X. CHRONIC PAIN, STIGMA, AND OPIOID CONTRACTS: A

POPULATION-LEVEL BIOETHICS ANALYSIS ....................... 109

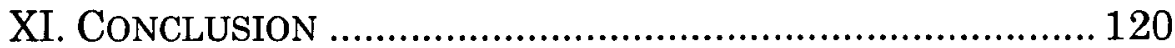

* Daniel S. Goldberg, Assistant Professor, The Brody School of Medicine, East Carolina University; J.D., University of Houston Law Center; Ph.D., Medical Humanities, Institute for Medical Humanities, University of Texas Medical Branch.

** Ben Rich, Professor and School of Medicine Alumni Association Endowed Chair of Bioethics, University of California, Davis; J.D., Washington University in Saint Louis School of Law; M.A. \& Ph.D., University of Colorado, Boulder. 


\section{INTRODUCTION}

In this paper, we critique the increasingly prevalent approach in pain management that urges the universal adoption of medication adherence contracts (so-called "opioid contracts") and random urine drugs screening as tools for managing the risk involved in prescribing and consuming opioid analgesics. Although the use of such opioid contracts and drug screening has received some recent attention in the bioethics literature, in this paper we advance new lines of criticism. We develop these criticisms in context of the use of opioid contracts through both dyadic and population-level perspectives, a combination of approaches that have rarely been deployed simultaneously in the bioethics literature on the undertreatment of pain. In the first portion of the paper, we criticize the turn to opioid contracts through analysis of the physician-patient relationship. We discuss several models of the relationship, and document the infirmities of a contractual model, which underpins the justification for opioid contracts. We move on to enumerate the essential elements of informed consent in context of the care of patients with chronic pain, and argue that properly understood, applied, and documented, scrupulous adherence to informed consent offers all of the benefits and none of the burdens of opioid contracts. We conclude the first segment of our paper by describing the "universal precautions" approach to opioid therapy that has been highly touted in recent years, and in the process identify our particular concerns with regard to it.

The second portion of the paper balances the prior emphasis on the therapeutic dyad with a macrosocial approach leveraging techniques drawn primarily from population-level bioethics. The focus here is on the likelihood that widespread utilization of opioid contracts will intensify the stigmatization of chronic pain sufferers, an already highly-stigmatized group that is in turn disproportionately composed of other disadvantaged and stigmatized social groups. Here, we define and operationalize disease stigma, explain why it is a pressing population-level bioethics issue on both descriptive and 
normative grounds, and show how the use of opioid contracts as part of a universal precautions approach is much more likely to intensify than to ameliorate stigma, contrary to the claims of its proponents. We apply Powers and Faden's sufficientarian account of social justice as a way of grounding the normative claim that the intensification of stigma is ethically unacceptable because it is both independently associated with adverse health outcomes and because it constitutes a particularly pernicious form of social disadvantage that is disproportionately likely to impact already marginalized groups.

Before proceeding to the argument, it is important to note two caveats. First, we wish to emphasize our belief that one of the primary obstacles to ameliorating the devastating and inequitable undertreatment of pain in the United States is the conflation of this problem with the problem of safe and effective utilization of opioids. Of course, both the undertreatment of pain and the safe and effective utilization of opioids are public health problems. However, there are profound clinical, empirical, and conceptual reasons to doubt that even the achievement of a reasonable opioid regulatory regime will substantially improve the undertreatment of pain in the United States. As we have documented these claims and the rationale for them elsewhere, we mention it here only to contextualize our present objectives, which are indeed focused on the use of opioids in the treatment of chronic noncancer pain. ${ }^{1}$ Notwithstanding our focus in this article, nothing argued herein should be taken as contrary to our belief that the undertreatment of pain and the safe and effective use of opioids are distinct public health problems, and that conflating them is a serious mistake. Second, for purposes of this article, we wish to focus on a particular category of pain and a very specific aspect of treating it. Our special concern and focus will be patients with moderate to severe

1 Daniel S. Goldberg, Job and the Stigmatization of Chronic Pain, 53 PersP. BIOLOGY MED. 425 (2010); Daniel S. Goldberg, On the Erroneous Conflation of Opiophobia and the Undertreatment of Pain, 10 AM. J. BIOETHICS, no. 11, 2010, at 20. 
chronic noncancer pain and whether the prevailing standard of care for prescribing opioid analgesics requires the use of a formal, written opioid contract that includes a provision for random urine drug screens, as a condition precedent for providing such therapy to any patient.

We begin the substantive analysis by delving into some of the social and political context regarding the rise of opioid contracts and the undertreatment of pain.

\section{The Convergence of Two Perfect Storms}

Beginning in earnest in the early 1990s, governmental agencies and health professional organizations acknowledged increasing evidence of pervasive undertreatment of pain. One early response to this phenomenon was the convening of interdisciplinary panels of experts by the Agency for Health Care Policy and Research and the promulgation of two extensive Clinical Practice Guidelines. ${ }^{2}$ Eventually undertreated pain of all types came to be recognized as having reached epidemic proportions and a becoming a world-wide public health problem. $^{3}$ The normative dimension of tolerating the unnecessary affliction of so many prompted advocates to demand recognition of pain management as a fundamental human right. 4 Still more recently, the Institute of Medicine ("IOM") report Relieving Pain in America characterizes

2 AGENCY FOR HEALTH CARE POLICY AND RESEARCH, U.S. DEP'T OF Health and Human Servs., Clinical Practice Guideline (No. 1): Acute Pain Management: Operative or Medical Procedures and Trauma (1992); AGENCY FOR HEALTH CARE POLICY AND RESEARCH, U.S. DeP'T of Health and Human Servs., Clinical Practice Guideline (No. 9): MANAGEMENT OF CANCER PAIN (1994); World Health Organization [WHO], Access to Controlled Medications Programme, Improving Access to Medications Controlled Under International Drug Conventions (Feb. 2009), available at http://www.who.int/medicines/ areas/quality_safety/ACMP_BrNoteGenrl_EN_Feb09.pdf.

3 See WHO, supra note 2.

4 See Frank Brennan et al., Pain Management: A Fundamental Human Right, 105 ANESTHESIA \& ANALGESIA 205, 211 (2007). 
effective pain management as a "moral imperative" and a "professional responsibility." 5

Between the mid-1990s and the present, data strongly indicate that in the United States there has been an exponential increase in the retail sales of opioid analgesics, a main line form of treatment for moderate to severe pain. ${ }^{6}$ During roughly the same period deaths associated with the ingestion of opioids dramatically increased as well- $142 \%$ increase between 1999 and 2004. ${ }^{7}$ There are also an increasing number of articles in the medical literature calling into serious question the safety and efficacy of opioids for the management of chronic pain over prolonged periods of time. ${ }^{8}$ However, there is a post hoc ergo propter hoc quality to some declarations that the pendulum has now swung too far away from the era of rampant opiophobia to the present when physicians allegedly are with reckless abandon prescribing opioids to anyone who complains of pain. ${ }^{9}$ Such pronouncements fail to take account of the many potential sources, other than prescriptions written for pain patients, by which those who abuse or are addicted to drugs may obtain these medications. ${ }^{10}$

Moreover, data indicate that both in the United States and worldwide we are a very long way from winning the

5 Inst. OF MEdicine, Relieving PAIN in AMERICA: A BluEprint For Transforming Prevention, CARe, EduCATION, AND REsearCH 3 (2011), available at $\mathrm{http}$ ://books.nap.edu/openbook.php?record_id= 13172 .

6 See Dennis C. Turk et al., Treatment of Chronic Non-Cancer Pain, 377 LANCET 2226, 2227 (2011).

7 See Jane C. Maxwell, The Prescription Drug Epidemic in the United States: A Perfect Storm, 30 DRUG \& ALCOHOL REV. 264 (2011).

8 See Paul F. White \& Henrik Kehlet, Improving Pain Management: Are we Jumping From the Frying Pan into the Fire? 105 ANESTHESIA \& ANALGESIA 10, 11 (2007).

9 See Jane C. Ballantyne \& Naomi S. Shin, Efficacy of Opioids for Chronic Pain: A Review of the Evidence, 24 CliniCAL J. PAIN 469, 469 (2008).

10 See Human Rights Watch, Global State of Pain Treatment: ACCEss TO MEDICINES AND PALliATIVE CARE (2011), available at http://www.hrw.org/sites/default/files/reports/hhr0511W.pdf. 
still formally undeclared "War on Pain."11 At the same time, the long-standing "War on Drugs" is shifting so as to accommodate a focus on the exponential increase in the abuse of prescription drugs. In a sincere effort by leaders in the pain medicine community to demonstrate an awareness of and appropriate concern for the recent epidemic of prescription drug abuse, the policy mantra has become one of balance, epitomized by the shared goals of insuring that pain patients receive the medications they require while at the same time minimizing the risk that such prescriptions will be abused or be diverted to others with no medical need for them. ${ }^{12}$ One of our special concerns is that the mantra of balance has not been restricted to the policy realm of state and federal laws and regulatory policies. Recently it has come to be viewed by some thought leaders as an essential component of "pharmacovigilence," or responsible opioid prescribing, and thereby required in order to practice consistent with the minimal standard of acceptable care. This move, we believe, presages a dramatic shift in the ethos of medicine and the fiduciary nature of the physicianpatient relationship. To these concerns we now turn.

\section{OPIOID CONTRACTS AND THE STANDARD OF CARE FOR CHRONIC OPIOID THERAPY}

In a recent commentary by three prominent pain medicine specialists, the authors noted that in 2010 an expert multidisciplinary panel commissioned by the Department of Defense ("DoD") and the Veterans Health Administration ("VHA") had completed a two-year systematic review of existing medical literature in the field of pain management and concluded that "opioid treatment agreements are a standard of care when prescribing chronic

11 See David E. Joranson \& Aaron M. Gilson, A Much-Needed Window on Opioid Diversion, 8 PAIN MED. 128 (2007).

12 PaIN \& POLICY STUdies GRP., UNIV. OF Wis., ACHIEVING Balance in State Pain Policy - A Progress Report Card (4th ed.) (2008). 
opioid therapy."13 Since the comprehensive clinical practice guideline implemented by the VHA recommend that such agreements should be obtained from all VHA patients prior to the initiation of opioid therapy, and that such agreements shall contain a provision whereby the patient consents to periodic unscheduled drug screens, we interpret the above quoted language as an assertion that the currently prevailing national standard of care requires a formal opioid contract and random urine drug screens for all patients undergoing opioid analgesia. ${ }^{14}$ We note, however, that the VA/DoD guideline does not preclude initiation of opioid therapy if a patient refuses to execute an opioid agreement. Rather, it provides that "[p]atient refusal to sign an agreement should be documented in the medical record" and considered "part of the initial and ongoing assessments of the patient's ability to adhere to the treatment plan and level of risk for adverse outcomes." 15

We shall presume that included in the VHA/DoD review of the medical literature were the Federation of State Medical Boards Model Policy for the Use of Controlled Substances for the Treatment of Pain, the expanded articulation of this model policy in a guidebook for clinicians under the title Responsible Opioid Prescribing, and the American Pain Society/American Academy of Pain Medicine Clinical Guidelines for the Use of Chronic Opioid Therapy in Chronic Noncancer Pain. ${ }^{16}$ However, none of these publications supports the position that the minimal

13 Scott M. Fishman et al., The Opioid Agreement: A Real-World Perspective, 10 AM J. Bioethics no. 11, 2010, at 14.

14 Veterans Admin. \& DeP'T of Def., Clinical Practice GUIDELINE FOR MANAGEMENT OF OPIOID THERAPY FOR CHRONIC PAIN 3134 (2010), available at http://www.healthquality.va.gov/COT_312_Fuller.pdf.

15 Id. at $32-33$.

16 See MOdel Policy For THE Use of CONTROLled Substances FOR THE TREATMENT OF PAIN (2004) (Fed'n of State Med. Bds.), available at http://www.fsmb.org/pdf/2004_grpol_Controlled_Substances.pdf; Scott M. Fishman, Responsible OpIOID PREscRibInG: A PHYsician's GuIDE (2009); Roger Chou et.al, Clinical Guidelines for the Use of Chronic Opioid Therapy in Chronic Noncancer Pain, 10 J. PAIN 113 (2009), available at http://download.journals.elsevierhealth.com/pdfs/journals/ 1526-5900/PIIS1526590008008316.pdf. 
standard of acceptable care for chronic opioid therapy requires a formal, written opioid agreement and random urine drug screens for all patients as a kind of "universal precaution." On the contrary, their consistent recommendation is that physicians should use their clinical knowledge, skills, and judgment in order to assess whether the patient presents an increased level of risk that would warrant the use of an opioid agreement. From this perspective, the insistence of some clinicians that opioid agreements and random urine drug screening should be a "universal precaution" might reasonably be interpreted as an abdication of one's professional responsibility to make such an assessment and utilize it as a basis upon which to determine whether a formal written contract and random urine drug screening is warranted. Further exploration of this possibility requires a brief discussion of the foundations for that responsibility.

\section{Competing Models of the Physician-Patient RELATIONSHIP}

A detailed discussion of the extensive literature comparing, contrasting, and evaluating various models of the physician-patient relationship is beyond the scope of this article. However, a more focused consideration of two of these-the contractual and the covenantal-are particularly relevant to the legitimate role, if any, of formal written agreements between physician and patient in certain clinical situations. One particularly influential analysis offered by Robert Veatch sought to distinguish among four possible models: (1) the Priestly (paternalism), (2) the Engineering (physician as technician), (3) the Collegial (physician and patient as fully equal parties), and (4) the Contractual. ${ }^{17}$ According to Veatch only the contract model could stand up to rigorous critical analysis at least in part because it appears to be consistent with the shared

17 Robert M. Veatch, Models for Ethical Medicine in a Revolutionary Age: What Physician-Patient Roles Foster the Most Ethical Relationship, 2 HASTINGS CENTER REP. 5 (1972). 
decision-making antidote to paternalism that respect for patient autonomy seemed to require.

Other prominent commentators seriously question the adequacy of a contractual model to exemplify not merely the fiduciary nature of the physician-patient relationship, in particular the physician's virtually unqualified professional responsibility to pursue the best interests of the patient and to recognize the patient's exquisite vulnerability in the face of illness. ${ }^{18}$ At least since the Hippocratic era, those who enter the medical profession swear an oath to direct their professional energies toward the restoration and maintenance of the health of their patients above all else. The very nature of this oath conveys the strong sense of a covenantal relationship as the defining nature of the therapeutic dyad. The imbalance of knowledge and power is the central feature of any fiduciary relationship. This intrinsic imbalance is inconsistent with the contractual paradigm of an agreement between relatively equal parties mutually endorsing fully and freely negotiated terms. Unequal parties do regularly enter into contracts, but the result is often regarded in law as a "contract of adhesion," a term of art denoting that the contract is a standard form drafted by and reflecting the interests of the stronger party which the weaker party must accept or reject "as is" with no opportunity for meaningful negotiation. ${ }^{19}$

Furthermore, in 1995 eight prominent physicians published a brief but cogent thought piece entitled "PatientPhysician Covenant."20 The thrust of the piece is captured in the following passage:

Medicine is, at its center, a moral enterprise grounded in a covenant of trust. . . . Physicians, therefore, are both intellectually

18 See, e.g., Edmund D. Pellegrino \& David C. Thomasma, A Philosophical Basis of Medical Practice (1981); WM. F. MaY, The Physician's Covenant: IMAGES OF THE HEALER IN MEdical ETHICS (2d ed. 2000).

19 See, e.g., A.R. Holder, What Is a Contract of Adhesion? 13 IRB: ETHICS \& HuM. SUBJECTS RES. 10 (1991).

20 R. Crawshaw et al., Patient-Physician Covenant, 273 JAMA 1553 (1995). 
and morally obliged to act as advocates for the sick wherever their welfare is threatened and for their health at all times. . . . Only by caring and advocating for the patient can the integrity of our profession be affirmed. Thus we honor our covenant of trust with patients. ${ }^{21}$

The responsibility of the physician to take on an advocacy role to ensure that the patient's needs for necessary or medically indicated treatment has been recognized by medical-legal commentators and medical organizations. ${ }^{22}$ Recognition of this professional responsibility reinforces the proposition that the pursuit of the patient's medical needs supersedes concerns about broader societal issues in the absence of any clear indication that the patient's conduct may imperil his/her own health as well as pose a threat to others.

Finally, in a recent special issue of the American Journal of Bioethics devoted to the issue of opioid contracts for chronic pain management, one commentator wrote of "the physician's covenant with the patient in pain."23 Invoking May's conceptual analysis of the physician's covenantal relationship with the patient, the author argues:

If physicians wish to remain true professionals, and not merely replaceable technician-cogs in the machinery of modern industrialized medicine, then physicians must strive to treat the patient as a covenantal partner rather than a consumer subject to a contract. . . As a tool to help reinforce that relational expectation, a written memorandum from physician to patient, adjusted to the

22 See, e.g., Wm. Sage, Physicians as Advocates, 35 Hous. L. REv. 1529 (1999); accord AMERICAN ACADEMY OF PAIN MEDICINE, ETHICS CHARTER (2008), available at http://www.painmed.org/files/ethicscharter.pdf.

23 Robert L. Fine, The Physician's Covenant with Patients in Pain, 10 AM. J. BIOETHICS 23 (2010). 
patient's medical literacy, is certainly ethically appropriate and may be practically useful. However, having the patient sign the memorandum as a contract is neither. ${ }^{24}$

Despite ongoing expression of concerns, there has been qualified support for adopting a contractual approach to at least certain aspects of patient care. It is important to consider the nature and limitations of that support before moving into a more targeted consideration of the ethical and legal dimensions and implications of opioid contracts.

\section{A BRIEF History OF THE UsE OF PHYSICIAN-PATIENT CONTRACTS}

Formal written contracts between physicians and patients, as documents separate and distinct from the usual and customary consent forms, are uncommon in most areas of clinical practice. Proponents of the use of such contracts in certain patient care situations often cite an early article that makes the case for a contractual approach as promoting "partnerships in patient care."25 Such a contractual approach, the author of that article maintains, is based on four assumptions: 1) both physician and patient have unique responsibilities in the relationship; 2) the relationship itself is voluntary and consensual, not obligatory; 3) both physician and patient must be willing to compromise in negotiating the terms of the contract; and 4) both parties must find benefit in the relationship that are reflected in the terms and conditions of the contract. ${ }^{26}$ Curiously, there is no discussion in the article about the doctrine of informed consent, the concept of shared decision making, or the relationship between those and a contractual model of the physician-patient relationship. There are several interesting aspects of the article that bear upon the specific phenomenon of opioid contracts. One is that the

$24 \quad I d$

25 Timothy E. Quill, Partnerships in Patient Care: A Contractual Approach, 98 ANNALS INTERNAL MED. 228 (1983).

$26 \quad I d$. 
typical opioid contract in use today is not the result of a negotiation between the physician and a particular patient, but rather a boilerplate form to which all patients must subscribe in order to receive opioid therapy, in other words, the quintessential contract of adhesion. Second, among the clinical vignettes discussed by Quill, the very first involves a patient undergoing long-term opioid therapy for chronic noncancer pain. ${ }^{27}$

One medical specialty that, even before the Quill article, had embraced the use of contracts is psychiatry, at least for patients who were deemed to pose a risk of suicide. ${ }^{28}$ Nevertheless, in a recent review of the practice, the authors critique the way in which such agreements are now used and note the paucity of any solid evidence that they are effective. ${ }^{29}$ The agreement, consisting merely of a request that the patient affirm that she or he would not take her or his life, was originally conceived as an assessment tool. If a patient refused to make such a vow or sought to limit or qualify it, then they were deemed to be at increased risk of suicide. ${ }^{30}$ In practice over the years, the concept of a nosuicide contract has morphed into an actual contract between patient and physician by which the patient commits not to engage in self-harm. One of the concerns expressed about this transformation is that the physician may rely excessively on the existence of the contract and fail to perform a careful assessment of the suicide risk, heavily exaggerating the patient's willingness or ability to report suicidal thoughts or impulses. ${ }^{31}$

An alternative approach to suicide prevention in psychiatry has been advocated that calls for a greatly reduced emphasis on formal written contracts in favor of a

27 Id. at 228.

28 See Robert C Drye et al., No-Suicide Decisions: Patient Monitoring of Suicidal Risk, 130 AM. J. PSYCHIATRY 171 (1973).

29 Keelin A. Garvey et al., Contracting for Safety with Patients: Clinical Practice and Forensic Implications, 37 J. AM. ACAD. PsYCHIATRY \& L. 363 (2009).

$30 \quad$ See Drye et al., supra note 28.

31 See Garvey et al., supra note 29. 
robust informed consent process. ${ }^{32}$ Many of the criticisms and concerns raised by these authors about the widespread practice of using suicide-prevention contracts are equally applicable to opioid contracts. For example, if the primary motivation for a contract is to meet a need or concern of the clinician, the result may be to undermine rather than promote establishment of a strong therapeutic alliance. The authors note, "Patients are very sensitive to actions meant to protect clinicians but presented in the guise of being in the patient's interests." 33 Insistence on a contractual agreement can adversely affect the patient's motivation to engage meaningfully in the development of and adherence to a treatment plan. And just as critics of no-suicide contracts contend that they can reasonably be viewed as a form of defensive medical practice, the "risk management" motivation suggested by the proliferation of opioid contracts is not diminished by the abundance of rhetoric by their proponents that these instruments are truly in the best interests of all concerned.

It is interesting to note the areas of clinical practice where one might have expected to find the use of contracts, particularly if the assertions of the proponents of opioid contracts were valid, but where in fact the medical literature suggests that they are not common. A relatively recent Cochrane review considered "contracts between patients and healthcare practitioners for improving patients' adherence to treatment, prevention, and health promotion activities." 34 This review assessed the quality of published data and the strength of evidence concerning the efficacy of such contracts. The aspects of patient care for which published data was available for consideration included the following: treatment of patients with addiction

32 See Michael Craig Miller et al., Talisman or Taboo: The Controversy of the Suicide Prevention Contract, 6 HARV. REV. PSYCHIATRY 78 (1998).

33 Id. at 81.

34 Xavier Bosch-Capblanch et al., Contracts Between Patients and Healthcare Practitioners for Improving Patients' Adherence to Treatment, Prevention and Health Promotion Activities, CoCHRANE Database Systematic Revs. no. 2, 2007, Art. No.: CD004808. DOI: 10.1002/14651858.CD004808.pub.3. 
disorders, hypertension, obesity (weight control), as well as a small number of miscellaneous studies concerning patients with diabetes, arthritis, and tuberculosis. Opioid therapy was not among those listed, nor was solid organ transplantation or chemotherapy for treatment of various malignancies. The absence of published data indicating that contracts are routinely used in other patient care situations where the risks of nonadherence are at least as significant as opioid analgesia tends to undermine the argument that opioid contracts are essential tools for protecting patients from the risks of deviating from the prescribing clinician's parameters. The reviewers concluded that many of the clinical trials were of poor quality, involved small numbers of participants, and provided insufficient evidence upon which to base a recommendation for the routine use of contracts as a means of improving patient adherence..$^{35}$

Accordingly, much of the enthusiasm for opioid contracts has been completely detached from any solid evidence that they improve treatment efficacy. ${ }^{36}$ The reasoning of the proponents appears to be that the current absence of demonstrable evidence of the actual or potential harmful consequences of opioid contracts and random urine drug screens provides a sound basis upon which to conclude that they are beneficial. In this regard, the discussion noted above in the psychiatric literature about no-suicide contracts should provide at least some measure of concern that insistence and reliance upon contracts may in fact be both unnecessary and contraindicated.

Finally, lost in the rhetoric that zealously advocates for opioid contracts and random urine drug screens for all patients with chronic pain who are candidates for opioid therapy are the important cautionary points about the nature of nonadherence. One commentator describes as many as five types of nonadherence: undercompliance (nonuse and partial use), overcompliance, drug holiday, underuse followed by overuse before clinical visits (whitecoat phenomenon), and randomization (inconsistent use of

$35 \quad I d$

36 See Fishman et al., supra note 13. 
medication). ${ }^{37}$ Fishman and colleagues specifically note these varieties of noncompliance and the multiple reasons that may motivate or underlie both under and overutilization of prescription medications. Addiction or abuse is only one of many different possible causes of the latter. ${ }^{38}$ They go on to point out, "A temptation exists to assume that patients with chronic nonmalignant pain who are not adherent to a treatment regimen are abusing medications. Other causes of nonadherence . . . must be addressed in this population." 39 They also note that "[i]mplementing and informing patients of ongoing adherence monitoring do not, in and of itself, assure good compliance . . . improving the ability of clinicians to discern nonadherence from ineffective therapy as the cause of drug failure will likely have substantial effect on treatment efficacy and safety." 40

We now turn to the consideration of informed consent. The pain medicine literature discussing opioid contracts we will consider in subsequent sections of this article treats informed consent as an important element of opioid therapy, but not one obviates the need for opioid contracts. We argue that such thinking reflects an exceedingly narrow, rigid, and ultimately impoverished conceptualization of informed consent and its role in enhancing a shared understanding and purpose in pursuing a particular form of therapy.

\section{INFORMED CONSENT}

The irrational exuberance many physicians have expressed for the indiscriminate use of opioid contracts strongly suggests a common belief that these documents provide a benefit which cannot be achieved through

37 Joseph a. Paladino, Am. Coll. of Clinical Pharmacy, Is COMPLIANCE WITH OUTPATIENT RX THERAPY COMMON? (1991).

38 Scott M Fishman et al., Adherence Monitoring and Drug Surveillance in Chronic Opioid Therapy, 20 J. PAIN \& SYMPTOM MGMT. 293, 295 (2000).

39 Id. at 304

40 Id. at 303. 
adherence to a thorough, ongoing, and well-documented informed consent process, and that this benefit outweighs any potential harm to the patient or the mutual trust and respect that is essential to the establishment and maintenance of a sound physician-patient relationship. We respectfully disagree and will make the case that informed consent as originally conceived would provide all of the purported benefits and reduce or eliminate many of the potential harms posed by opioid contracts.

The duty to obtain an informed consent and to document the pertinent details of that consent in the medical record has been well-established in both American law and bioethics for decades for all but the most minimal and benign of medical interventions and therapies, and would certainly be required for treatment with opioid analgesics. ${ }^{41}$ For purposes of this discussion, it should suffice to simply reiterate the essential elements of an informed consent and well-recognized principles for engaging in the informed consent dialogue, because in doing so it becomes clear why a written contract concerning opioid therapy is unnecessary unless the requisites of the informed consent doctrine have not been met.

\section{A. Elements of Informed Consent as They Relate to Pain Management}

A starting point is the diagnosis, along with an explanation of how and why the intervention will be likely to rule in or rule out one or more of the likely possibilities. In the case of opioid therapy, it is important for both the clinician and patient to understand that in contemporary medical thought chronic pain may well be a diagnosis rather than merely a symptom of some underlying disease or injury. ${ }^{42}$ The second element of informed consent is a discussion of the nature of the therapeutic intervention.

41 Ben A. Rich, A Prescription for the Pain: The Emerging Standard of Care for Pain Management, 26 WM. MiTCHELL L. REV. 1 (2000).

42 NAT'L CTR. FOR HeAlTH STATISTICS \& CTRS. FOR MEDICARE AND MEDICAID SERVS., ICD-9-CM (6th ed. 2009). 
When this involves chronic opioid therapy, some basic discussion of the properties of the medication or medications to be prescribed should be provided, including how and why the medication(s) functions to relieve pain. A third element is the patient's prognosis with and without the recommended treatment. Prognostication is considered much more uncertain than diagnosis because of the many other factors influencing how patient's react to and cope with illness, as well as their willingness and ability to adhere to a therapeutic regimen. This may be particularly true of chronic pain patients on opioid therapy, which makes candid exchanges and regular follow-up all that more important.

A fourth element of consent-the anticipated benefits and risks of treatment-is perhaps the most critical one with regard to our contention that a properly conducted informed consent process is the optimal means of achieving the purported objectives of opioid contracts. This may be the most challenging part of the informed consent process for opioid analgesia because of the absence of solid clinical evidence for most of the recommendations found in current medical treatises and guidelines. ${ }^{43}$ Because of the level of concern about the percentage of patients on chronic opioid therapy who may have or develop a propensity for aberrant drug behaviors, the risks to be discussed with each patient must include both those intrinsic to opioid therapy, as well as the greatly increased risks to the patient if the medication(s) is not taken as directed. ${ }^{44}$ In the discussion of the anticipated benefits of opioid therapy, the prescribing physician should make clear what she or he believes to be the realistic goal. There is now a strong consensus in the pain medicine community that simply achieving and maintaining a modicum of reduction in pain levels is not a goal of treatment worthy of assuming the risks of long-term opioid analgesia. It is essential, according to many thought

43 Roger Chou et al., supra note 16.

44 Dennis C. Turk et al., Predicting Opioid Misuse by Chronic Pain Patients: A Systematic Review and Literature Synthesis, 24 ClINICAL J. PAIN 497, 506-07 (2008). 
leaders in the field, that the goals of treatment include improvement in the level of function. ${ }^{45}$

The recent emphasis in pain medicine that chronic opioid therapy cannot be deemed effective if only reduction in the levels of reported pain is achieved, but without demonstrable functional improvement, has a somewhat paternalistic if not authoritarian character. It relegates the assessment of benefit entirely to the prescribing physician. Ultimately, it is the patient who must assume the risks and bear the burdens of any medical intervention, as well as endure the pain, suffering, and disability associated with the underlying condition. The victims of moderate to severe chronic pain are often desperate for some measure of deliverance from distress, and therefore may be willing to assume risks that someone who has never shared their experience, including clinicians, would consider to be excessive. While accurate medical information is essential to the risk/benefit calculation, ultimately it is a normative and subjective, not purely scientific and objective determination that each patient must reach, as with any other treatment decision.

The final element of an informed consent involves consideration of the alternatives to the recommended treatment and the anticipated risks and benefits each would involve. Of course, in all clinical situations, there is always at least one other option to the recommended treatment, i.e., doing nothing. This too involves risks, particularly if the recommended treatment is deemed medically necessary.

\section{B. Important Considerations in the Process of Informed Consent for Pain Therapy}

Informed consent, properly understood and practiced in clinical medicine, is an ongoing process, and in no situation is that true more than in the management of chronic pain. This notion is confirmed by the way in which opioid therapy as a treatment option has come to be characterized in the

45 See, e.g., Amber Huntzinger, Guidelines for the Use of Opioid Therapy in Patients with Chronic Noncancer Pain, 80 AM. FAMILY PHYSICIAN 1315 (2009). 
literature, i.e., as a "trial." 46 An initial treatment plan and the goals it is formulated with the intent of pursuing is an essential feature of the consent process. Consequently, that plan, and the efficacy of the specific measures undertaken to achieve its purposes, must be periodically evaluated based upon the patient's experience. This process is absolutely essential to shared decision making within the therapeutic dyad.

One reason why some clinicians view consent as a discrete event, even outside the context of surgery, is an obsessive focus on the signing of the consent form. The form is simply a piece of documentary evidence. This is just one reason why the wholesale adoption of opioid contracts is problematic. As we will discuss more fully in a subsequent section, such contracts tend to take a certain form, consisting of a long list of "thou shalts" and "thou shalt nots" to which the patient is expected to unquestioningly agree in order to be provided opioid analgesia. There is no genuine meeting of the minds or any effort to tailor the agreement to a specific treatment plan in the formulation of which the patient has played any meaningful role. ${ }^{47}$

When a patient executes a written consent to opioid therapy she or he is explicitly agreeing to adhere to the treatment regimen, particularly taking the medications as directed. Such directions will likely include not only the specific medication(s) and dosage, but also the proviso that no similar medications will be sought from other physicians. Consent to the treatment plan will also include a commitment to regular follow-up appointments to reassess the efficacy of treatment and the presence of any complications from the prescribed medications. So understood, the detailed written consent covers all important aspects of sound opioid therapy and contains many of the uncontroversial provisions of an opioid contract, but does so in a way that does not single out chronic pain patients as do separate opioid contracts.

46 See Chou et al., supra note 13 , at 115-16.

47 Robert M. Arnold et al., Opioid Contracts in Chronic Nonmalignant Pain Management: Objectives and Uncertainties, 119 AM. J. MED. 292, 293-95 (2006). 
Properly understood and appreciated, the informed consent process is not merely a boilerplate form that the patient must be persuaded to sign with a minimum of examination and explanation. We are not alone in our advocacy of it as a means of establishing and enriching the therapeutic dyad. Particularly in areas fraught with uncertainty and challenge, of which opioid therapy for chronic pain is a prime example, it allows thoughtful and engaged physicians to acknowledge the profound level of uncertainty that pervades many aspects of patient care. ${ }^{48}$

There is, however, one aspect of the informed consent process that may require modification if it is to serve as superior alternative to an opioid contract. Out of respect for individual autonomy, patients are allowed to decline to receive information about the nature of a proposed therapy and its benefits, risks, and alternatives. However, the emerging paradigm of responsible opioid prescribing essentially requires that the physician impart to the patient what is expected of her in order to safely embark upon a trial of opioid analgesia. Thus, it may not be acceptable practice to allow patients to cultivate their ignorance of the conditions upon which a course of opioid therapy will be undertaken. With this perspective on informed consent and the recommended process by which it is used to facilitate shared decision making on a treatment plan, we now turn to the most common elements of opioid contracts in an effort to ascertain whether they offer anything to physician or patient that cannot be achieved through clear documentation of the process described above.

\section{OPIOID CONTRACTS IN THE MANAGEMENT OF CHRONIC} PAIN

Discussion of opioid contracts for chronic pain patients undergoing opioid therapy is a relatively recent phenomenon. Much of the early analysis of this phenomenon in pain medicine was done by Fishman and

48 See, e.g., Thomas G. Gutheil et al., Malpractice Prevention Through the Sharing of Uncertainty: Informed Consent and the Therapeutic Alliance, 311 NEW ENG. J. MED. 49 (1984). 
colleagues ten to twelve years ago. Even then, however, they reported that "contracts are widely used in the chronic administration of potentially abusable substances or management of lethal behaviors." 49 Fishman and colleagues found that by far the most common provisions in the thirty-nine contracts they reviewed dealt with the following: commitment by patient to avoid improper use of controlled substances (95\%), specification of terms for disciplinary termination of the patient for violating the contract or engaging in other inappropriate behavior (92\%), limitations on replacing medications or changing prescriptions $(85 \%)$, providing physicians with relevant information $(74 \%)$, and submission to random urine drug screens (69\%).50 At the opposite end of the continuum, the least common provisions of these contracts were those that affirmed any joint responsibility of physician and patient for opioid therapy (5\%), documented physician obligations under the contract (3\%), or acknowledged the physician's obligation to provide treatment information to the patient $(3 \%) .51$

Fishman and colleagues further observed that "very few of the reviewed contracts suggest patients have any role in determining their terms.52 Consequently, while these authors suggest that in some idealized sense the contract "is intended to enhance the therapeutic relationship by initiating and supporting an alliance between the patient and the physician," 53 it is very difficult to discern how the typical provisions they found in their survey would be conducive to that goal. Rather, the most typical provisions strongly suggest an approach by which the prescribing physician lays down the law governing the patient's conduct and empowers the physician to terminate the relationship forthwith in the event of any violation by the patient. Similarly, Collen's survey of private practitioners revealed

49 Scott M Fishman et al., The Opioid Contract in the Management of Chronic Pain, 18 J. PAIN \& SYMPTOM MGMT. 27, 27-28 (1999).

50 Id. at 30-31.

51 Id.

$52 \quad I d$. at 32.

$53 \quad$ Id. at 28. 
that the vast majority of contract provisions pertained to the consequences to the patient for violating any term of the agreement, rules regarding prescriptions and refills thereof, and submission to random urine drug screens. ${ }^{54}$ It is plausible to suggest that for many patients, the insistence upon execution of a written contract with a long list of seemingly harsh and unilateral conditions by a physician will be a unique and disturbing experience.

\section{THE UNIVERSAL PRECAUTIONS APPROACH}

Ever-increasing utilization of opioid contracts and mandatory random urine drug screening had already become a prominent feature of pain medicine specialty clinics by 2005 , when a seminal article advocating their use as a form of "universal precautions" in pain medicine was published. ${ }^{55}$ Mimicking the wholesale adoption of a universal precautions approach to infectious diseases such as HIV and hepatitis, the authors recommend that certain minimal precautions be taken with regard to "all chronic pain patients regardless of pharmacologic status."56 Underlying the application of the infectious disease model to chronic pain patients is the belief that identifying patients at risk of addiction or diversion is essentially as difficult as identifying patients with HIV or other serious infectious diseases and the consequences of a failure to do so equally perilous.

In addition to our previously mentioned observation that the universal precautions approach, insisting as it does on opioid contracts and random urine drug screens for all patients on opioid analgesia regardless of the level of risk assessed, is inconsistent with current national guidelines and model policies, we wish to note further the disanalogy

54 Mark Collen, Analysis of Controlled Substance Agreements from Private Practice Physicians, 23 J. PAIN \& Palliative CaRe PHARMACOTHERAPY 357 (2009).

55 See Douglas L. Gourlay et al., Universal Precautions in Pain Medicine: A Rational Approach to the Treatment of Chronic Pain, 6 PAIN MED. 107 (2005).

$56 \quad$ Id. at 109. 
between the two. Universal precautions in infectious disease are applied to all patients in all patient care settings. By contrast, not all patients receiving medications posing risks when not taken as directed are subjected to contract conditions and random urine drug screens; only those whose medically-indicated treatment includes an opioid analgesic are subject to those consequences. We will address in detail below the dubious claim that this application ameliorates the already prevalent stigmatization chronic pain sufferers who take opioids endure. For now, it is sufficient merely to note that this distinction undermines the analogy between the universal precautions approach as to infectious disease and that applied as to chronic pain sufferers for whom opioids are prescribed.

The universal precautions approach in pain medicine includes a total of ten elements, only one of which do we believe is problematic, or two if opioid contracts and random urine drug screens are treated separately. The enumerated precautions are as follows:

1. Diagnosis with appropriate differential;

2. Psychological assessment including risk of addictive disorders;

3. Informed consent;

4. Treatment agreement (including a provision whereby the patient agrees to random urine drug screens);

5. Pre-and post-intervention assessment;

6. Appropriate trial of opioid therapy $+/$ - adjunctive medications;

7. Reassessment of pain score and level of function;

8. Periodic assessment of 4 A's of pain medicine: analgesia, activity, adverse effects, aberrant behavior;

9. Periodic review of pain diagnosis and comorbid conditions including addictive disorders; and

10. Documentation.

Prior to listing these ten commandments of responsible opioid prescribing the authors offer the sweeping assertions 
that "by applying the following recommendations, patient care is improved, stigma is reduced, and overall risk is contained." 57 Neither argument nor any reference to the literature is provided in support of any of these claimed benefits. Similarly, in a more recent articulation of the universal precautions approach, Gourlay and Heit declare, "Universal precautions as a concept is based on mutual trust and respect between patient and practitioner alike."58 There is an Orwellian cast to the insistence that an effective means of demonstrating and promoting trust is for the empowered party in a relationship to demand that the disempowered party initially and continuously prove to the other by execution of a rigorous written contract and tangible evidence (urine drug screens) that they are upholding their pledge to access, utilize, and secure medications in strict accordance with doctor's orders. ${ }^{59} \mathrm{We}$ have already presented argumentation in support of the position that properly understood and implemented, documentation of the informed consent process achieves whatever benefits are believed to flow from a written opioid contract.

Our objection to opioid agreements and random urine drug screens for all patients undergoing a trial of opioid therapy is based upon an understanding that assessing the presence or risk of addiction, as well as the potential for abuse or diversion of opioids is a reasonable and perfectly acceptable universal precaution. This approach is consistent with national guidelines and model policies and implicitly ascribes a minimal level of efficacy for currently available approaches to assessment of risk, to which we now turn. Before doing so, however, it is important to emphasize how much more expansive and complicated is the universal precautions risk assessment for opioid

$57 \quad I d$.

58 Douglas L. Gourlay and Howard A. Heit, Universal Precautions Revisited: Managing the Inherited Pain Patient, 10 PAIN MED. S115, S116 (2009).

59 See Lisa Victor \& Steven H. Richeimer, Trustworthiness as a Clinical Variable: The Problem of Trust in the Management of Chronic, Nonmalignant Pain, 5 PAIN MED. 385 (2005). 
analgesia is than for most other medical treatments. Not only must the clinician arrive at a good faith medical judgment that the risks inherent in taking a particular opioid are outweighed by the reasonably anticipated benefits, but she or he is admonished to assess the risk that the patient might not strictly adhere to the treatment regimen or might not properly sequester the medication. Although it has been extensively documented that nonadherence is a widespread problem in clinical practice, assessing the risk of that for each patient prior to initiating treatment is not generally viewed as part of the minimal standard of acceptable care. The only possible exception might be solid organ transplantation. Because of the ongoing scarcity of viable organs for transplantation, it is important to identify and be prepared to support patients who are prime candidates for transplant but who present with factors suggesting that adherence may be challenging. ${ }^{60}$ Nevertheless, insistence upon written contracts signed by patients pledging adherence and submitting to monitoring protocols do not feature prominently in the transplantation literature.

It is beyond the scope of this article, and the competencies of the authors, to provide a detailed review and evaluation of the ever-increasing panoply of risk assessment tools upon which clinicians considering a trial of opioid therapy can draw. One overview lists nine of these. ${ }^{61}$ Some are relatively simple and straightforward and therefore lend themselves to primary care settings, whereas others are more elaborate and time-consuming to utilize, and hence likely to be more suited to specialized pain medicine clinics and referral centers. For our purposes, the important point is that responsible risk assessment and stratification of patients can be undertaken by clinicians

60 See Brigitta Bunzel \& Kurt Laederach-Hofmann, Solid Organ Transplantation: Are There Predictors For Posttransplant Noncompliance? A Literature Review, 70 TransPLANTATION 711, 715 (2000).

61 Steven D. Passik \& Pamela. Sqyire, Current Risk Assessment and Management Paradigms: Snapshots in the Life of the Pain Specialist, 10 PAIN MED. S101, S104 (2009). 
consistent with current nationally promulgated clinical practice guidelines and model policies, supporting the reasonable exercise of clinical judgment as to whether a particular patient's situation warrants a heightened level of oversight and monitoring. The fact that such risk assessment is not foolproof is beside the point, since no physician is ever held to a standard of perfection. Any suggestion that written opioid contracts and random urine drug testing insures such perfection cannot stand careful scrutiny, as the next section will demonstrate.

\section{ADHERENCE MONITORING Through URINE DRUG SCREENING IN OPIOID THERAPY}

An article by Fishman and colleagues candidly reviews the challenges and limitations posed by various strategies to monitor adherence to opioid therapy. ${ }^{62}$ First, their review acknowledges the critical point that we will develop below that contracts have the potential to perpetuate stigma. Second, Fishman and colleagues, consistent with the above noted critiques of no-harm contracts in psychiatry, warn that opioid contracts may create the illusion of adherence and result in a lower level of clinical scrutiny in the followup. Third, on the matter of laboratory testing for opioids, these authors note that "[s]uch tests are often compromised by variability and limitations in obtaining specimens, custody of specimens, laboratory methodologies, and interpretation of laboratory data."63 There is a risk of both false negative and false positive results. Concentrations below the inherent limits of detection for a particular assay may result in a negative determination for a prescribed medication despite its actual presence in the patient. Oxycodone, for example, may not test positive at even at a therapeutic dosage. False positive results may be caused by something as innocuous as the ingestion of poppy seeds.

These authors also note that savvy clinicians should not jump to the conclusion that nonadherence with opioid therapy necessarily involves abuse. The broad range of

62 See Fishman et al., supra note 49.

63 Id. at 297. 
patient behaviors regarding nonadherence is consistent with other studies indicating that failure to strictly adhere to prescription medication regimens is a widespread phenomenon cutting across many clinical conditions and prescription drugs. ${ }^{64}$ Without careful inquiry into the type of nonadherence and the factors underlying it, clinicians may leap to erroneous conclusions that in turn lead to precipitous and unwarranted discontinuation of opioid therapy or in the most extreme cases discontinuation of the physician-patient relationship.

We turn now to the final portion of our argument against the use of opioid contracts and universal drug screening, in which we address the risks of stigmatization that attend the widespread use of such tools. Herein, we attempt to clarify some of the muddled thinking on the subject of stigma, which generally proceeds absent any informed theoretical understanding of the considerable literature on disease and health stigma, and we attempt to demonstrate the ethical harms that result from intensifying stigmatization of an already highly-stigmatized group (chronic pain sufferers). This final section balances the emphasis on the therapeutic dyad thus far with a macrosocial approach that focuses on the determinants of population health and relies on empirical evidence drawn primarily from social epidemiology. It is only through such a macro-level approach that the true health impact of stigma can be understood, and the ethical harms fully apprehended.

\section{Chronic Pain, Stigma, And OpIoId Contracts: A POPULATION-LEVEL BIOETHICS ANALYSIS}

As we have chronicled the rise of opioid contracts as a tool for universal precautions, we wish now to focus on one of the primary justifications offered for their use: that of avoiding stigmatization. Although this rationale is frequently cited, there is little literature that closely examines concerns of stigmatization as a justification for moving to the universal use of such contracts. This is 
surprising at least in part because good evidence indicates that stigmatization is a common companion for many chronic pain sufferers ${ }^{65}$ and that the risks and extent of such stigmatization are distributed disproportionately among various social strata (race, class, gender, age, etc.).66 Although precise quantitative evidence on the prevalence of chronic pain stigma is lacking, the available evidence suggests its commonality, intensity, and inequitable distribution. ${ }^{67}$ Disease stigma in general is an enormous clinical and ethical problem. Because it can worsen disease outcomes, imposes a distinct form of psychosocial suffering, and is independently associated with increased morbidities and mortalities, such stigma is a major public health problem. ${ }^{68}$ Moreover, as Burris points out, narratives of

65 E.g., Goldberg, Job and the Stigmatization of Chronic Pain, supra note 1, at 431; Carole C. Upshur et al., 'They Don't Want Anything to Do with You': Patient Views of Primary Care Management of Chronic Pain, 11 PAIN MED. 1791, 1794-95 (2010); Jean E. Jackson, Stigma, Liminality, and Chronic-Pain: Mind-Body Borderlands, 32 AM. ETHNOLOGIST 332 (2005); Anne Werner \& Kristi Malterud, It is Hard Work Behaving as a Credible Patient: Encounters between Women with Chronic Pain and their Doctors, 57 Soc. SCI. \& MED. 1409, 1414-15 (2003); Joseph J. Marbach et al., Losing Face: Sources of Stigma as Perceived by Chronic Facial Pain Patients, 13 J. BEHAV. MED. 583 (1990).

66 See Goldberg, Job and the Stigmatization of Chronic Pain, supra note 1; Jackson, supra note 65; Werner \& Malterud, supra note 65; Dania Palanker, Note, Enslaved by Pain: How the U.S. Public Health System Adds to Disparities in Pain Treatment for African Americans, 15 GEORGETOWN J. ON POVERTY L \& POL'Y 847 (2008).

67 See sources cited supra note 65 ; see also Palanker, supra note 66.

68 See, e.g., Rebecca M. Puhl \& Chelsea A. Heuer, Obesity Stigma: Important Considerations for Public Health, 100 AM. J. PUB. HEALTH 1019, 1019-20 (2010); J. Hong et al., The Psychosocial and Occupational Impact of Chronic Skin Disease, 21 DERMATOLOGIC THERAPY 54, 57-58 (2008); Peter A. Vanable et al.. Littlewood, Impact of HIV-Related Stigma on Health Behaviors and Psychological Adjustment among HIVPositive Men and Women, 10 AIDS Behav. 473, 479-80 (2006); Bruce G. Link \& Jo C. Phelan, Stigma and Its Public Health Implications, 367 LANCET 528, 528-29 (2006); D. Vardy et al., Experiences of Stigmatization Play a Role in Mediating the Impact of Disease Severity on Quality of Life in Psoriasis Patients, 147 BRITISH J. DERMATOLOGY $736,741 \cdot 42$ (2002). 
disease stigma "would by and large melt a heart of stone, so that even if [disease stigma] had no adverse effects on health or public health practice, it may readily be seen as repugnant in a humane society." 69

In addition, there is a well-developed literature on the significance of trust between the patient and the provider in both chronic disease management and chronic pain management in particular. ${ }^{70}$ Because the relationship between stigma and trust is profoundly inverse, it is essential to interrogate the presumed causal relationship between increased utilization of universal opioid contracts and decreased chronic pain stigma. We argue in this section that although the intention of ameliorating the absolute and inequitably distributed burdens of this stigma is laudable, the move to universal opioid contracts is both ill-advised and counterproductive, and it is much more likely to intensify chronic pain stigma than to ameliorate it. We further contend that this intensified stigmatization will disproportionately impact chronic pain sufferers in the most marginalized communities. We draw on Powers and Faden's account of social justice in health policy, which posits that actions that can be predicted to intensify the "densely-woven patterns of disadvantage" in which the most vulnerable and marginalized members of American society are situated are fundamentally unjust. ${ }^{71}$ Because universal opioid contracts are likely to intensify stigma and erode trust, they run a dangerously high likelihood of exacerbating such densely-woven patterns of disadvantage.

69 Scott Burris, Disease Stigma in U.S. Public Health Law, 30 J.L. MED. \& ETHICS 179, 182 (2002).

70 See Leonard E. Egede \& Yvonne Michel, Medical Mistrust, Diabetes Self-Management, and Glycemic Control in an Indigent Population With Type 2 Diabetes, 29 Diabetes CARE 131 (2006); Denise E. Bonds et al., The Association of Patient Trust and Self-Care Among Patients with Diabetes Mellitus, 5 BMC FAMILY PRACTICE 26 (2004); Thomas A. LaVeist et al., Attitudes about Racism, Medical Mistrust, and Satisfaction with Care among African American and White Cardiac Patients, 57 MED. CARE RES. \& REV. 146 (2000).

71 See Madison Powers \& RuTH Faden, Social Justice: The Moral Foundations of PUBlic Health and HeAlth POliCY passim, 71 (John Harris et al. eds., 2006). 
Given that there is a paucity of high-quality evidence showing significant benefits stemming from the use of universal opioid contracts, the very real harms that are likely to flow from their use renders their adoption ethically dubious.

First, as we have noted above, we reject the peculiar notion that universal opioid contracts, by virtue of their utilization among all chronic pain sufferers for whom opioids are prescribed, ipso facto diminish chronic pain stigma. The generally accepted notion of disease stigma stems from Goffman's seminal work ${ }^{72}$ and, as interpreted by Link and Phelan, ${ }^{73}$ consists of two central criteria: (1) a social group must mark another social group as different, by which process in-groups and out-groups are defined and branded, and (2) the in-group must assign a normative valence to the out-group; the out-group must be marked as deviant. Because the marking of difference and the assignment of deviance require actors, it is inevitably people who stigmatize other people. Moreover, the capacities to mark and to assign deviance are a function of the social, economic, and political power wielded by the in-group. ${ }^{74}$ This links stigma to larger social inequalities, a point we shall return to shortly. ${ }^{75}$

As applied to universal opioid contracts, there is little rationale for the prima facie claim often asserted in the literature on universal opioid contracts that marking an already highly-stigmatized subgroup as an out-group in this additional sense would inherently be likely to ameliorate that stigma. Moreover, the first portion of this definition of stigma shows the absurdity of the assertion that by virtue of their universality opioid contracts do not discriminate. Such contracts unquestionably mark out a social group as different, the social group in question being chronic pain sufferers who utilize opioid analgesics. Pain sufferers for whom opioids are either not indicated or are not

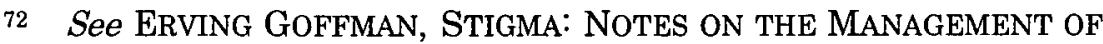
A SPOILED IDENTITY 126-160 (1963).

73 See Link \& Phelan, supra note 68 , at 528-29.

74 Id.

75 Id. 
prescribed-a larger group than the frenzied attention expended on opioids and pain would suggest-are not subjected to such contracts. Nor, to make the point more obviously, are adherence contracts utilized among patients for whom aspirin, beta blockers, or metformin is prescribed. Note here that the "difference" criterion of stigma is in theory distinct from the "deviance" criterion. Thus, the fact that chronic pain patients who take opioids are marked out as different does not necessarily show that the group is being stigmatized. However, it does repudiate the oftasserted and wholly unsupported idea that the utilization of universal opioid contracts somehow fails to discriminate, or mark out as different, a particular social group.

It is essential to ask why it is that opioid-taking chronic pain sufferers are being marked as different. The answers given rest on the risks said to inhere in the prescription and use of opioid analgesics, the most significant of which are those of addiction and diversion. This implies that the use of opioids is "risky," and that the "riskiness" of prescribing and taking opioids is what merits the differential treatment. In turn, the presumed riskiness of chronic pain sufferers who take opioids highlights Jean Jackson's point that chronic pain is properly regarded as a liminal state in American society.76 In countless ways, chronic pain sufferers exist on the borderlands, and the classification of those who take opioids reflects this point-not quite drug abusers or addicts, but certainly of social concern in ways that those who take metformin or ranitidine are not. Risk is of course a social phenomenon, which means it can spread along social networks; in this sense the riskiness of chronic pain patients that take opioids can flow to the physicians that prescribe those opioids, who undergo perceived risks in so doing and in turn become risky and liminal in and of themselves in the eyes of other social and institutional authorities such as state medical boards and law enforcement agencies. As Jackson points out, this liminality matters for chronic pain sufferers in particular because those whom societies regard as liminal are at

76 See Jackson, supra note 65; JEAN E. JACKSON, CAMP PAIN: TALKING WITH CHRONIC PAIN PATIENTS 102-108 (2000). 
heightened risk of being marked as different and regarded as deviant. ${ }^{77}$ Liminality in some contexts, chronic pain apparently being one of them, is a social marker for stigmatization.

While the definition of stigma allows for a conceptual distinction between marking of difference and assignation of deviance, there is unfortunately ample reason to believe that the risk of slippage is extremely high. Kurzban and Leary argue for a functional-evolutionary explanation of stigmatization that explains "the important question of why an inherently social species with a strong need for social acceptance should be so inclined to reject members of its own kind."78 They posit that stigmatization fulfills several evolutionary roles centering on the need for humans to avoid some of the intensely negative experiences of social life. ${ }^{79}$ Hence, Kurzban and Leary contend that "human adaptations for sociality include cognitive mechanisms that cause people to be selective in their social interactions."80 They conclude that the commonality of stigma in social life can be explained at least in part by these adaptations. ${ }^{81}$ If there is merit to this theory, it suggests that a neat and easily-made distinction between difference and deviance is not reflective of the real costs of social life and that stigmatization is rather a common adaptive mechanism for coping with and managing those costs.

In addition, the extremely common experiences of disease stigma in Western history cast serious doubt on the extent to which the theoretical distinction between difference and deviance can be maintained in practice. ${ }^{82}$ Thus even if we completely deny the evolutionary theory of stigmatization, disease stigma in the West is historically such a common occurrence as to belie the idea that an empowered group merely marking out a marginalized group

\section{$77 \quad I d$}

78 R. Kurzban \& M.R. Leary, Evolutionary Origins of Stigmatization: The Functions of Social Exclusion, 127 PSYCHOLOGICAL BULL. 187, 187 (2001).

79 Id.

$80 I d$ at 189.

81 Id.

82 See Goldberg, supra note 1. 
as different on the basis of a recognized disease will generally be socially innocuous. History suggests the contrary.

Furthermore, even granting for the sake of argument that the historic and easy slippage between difference and deviance somehow does not occur with a group that already endures much stigma, the suspicion enshrined in universal opioid contracts may have a disparate impact on already marginalized and vulnerable groups. The term "disparate impact" is a legal term of art, with roots in antidiscrimination law. The necessity for prohibition of legal regimes and frameworks that had disparate impacts became apparent during the Civil Rights Era in particular, taking shape in the seminal 1971 case of Griggs v. Duke Power Co.83 In that case, Duke Power Company ("Duke") instituted an intradepartmental transfer policy in 1955 for its employees that required completion of a high school education. ${ }^{84}$ Immediately subsequent to the effective date of Title VII of the Civil Rights Act, Duke added a second provision to the transfer policy, requiring putative transferees to "register satisfactory scores on two professionally prepared aptitude tests, as well as to have a high school education." 85 These requirements applied to all employees, whether Caucasian or African-American. ${ }^{86}$

Thirteen African-Americans filed suit under Title VII, arguing that the practices were discriminatory even though they were facially neutral. The U.S. Supreme Court agreed, noting that under the requirements white employees fared far better than their black counterparts, traceable in large part to the legacy of inferior education offered to AfricanAmericans in North Carolina, where the action arose. ${ }^{87}$ The Court reasoned that "absence of discriminatory intent does not redeem employment procedures or testing mechanisms that operate as 'built-in headwinds' for minority groups and

$\begin{array}{ll}83 & 401 \text { U.S. } 424(1971) . \\ 84 & I d . \text { at } 427 . \\ 85 & I d . \text { at } 427-28 . \\ 86 & I d . \text { at } 429 . \\ 87 & I d . \text { at } 430 .\end{array}$


are unrelated to measuring job capability." 88 Moreover, the Court noted, Title VII is directed at "the consequences of employment practices, not simply the motivation." 89

We utilize the disparate impact analysis here solely by way of analogy; that is, we are agnostic on the question of whether the use of universal opioid contracts gives rise to an actionable civil rights claim. Rather, we are focused on the ethical underpinnings of disparate impact analysis, which suggests that even policies that are universally applied can be intolerable if they have a disparate impact on an identifiable social group. Applied here, closer scrutiny suggests ample reason to believe that universal opioid contracts may have just such a disparate impact on those most vulnerable members of the communities of chronic pain sufferers that take opioids.

Regarding these communities, there are stark inequities in the diagnosis and treatment of chronic pain, inequities which revolve around social strata like race, class, gender, and rurality, among many others. ${ }^{90}$ Given the welldocumented fact that social disadvantages tend to cluster, those suffering from one form of social inequality are much more likely to experience the deleterious effects of other such inequalities.91 Thus, someone who is of low socioeconomic status is significantly more likely to have low educational attainment, work at a job for low pay, difficult hours, and no job autonomy, and be exposed to various health risks such as environmental hazards, violence, and forms of discrimination (racism, sexism, ageism, etc.). As Hilary Graham puts it, "[u]nequal social positions carry with them unequal probabilities of being exposed to health

\section{Id. at 432.}

$89 \quad$ Id. at 433.

90 The literature on this topic is explosive. For an excellent discussion and a list of sources, see INST. OF MEDICINE, supra note 5, at 2-9 through -26 .

91 See POWERS \& FADEN, supra note 71, at 71, passim; Jonathan Wolff, Disadvantage, Risk and the Social Determinants of Health, 2 Pub. Health ETHICS 214 (2009); Daniel S. Goldberg, Global Health Care is Not Global Health: Populations, Inequities, and Law as a Social Determinant of Health, in THE Globalization of HEALTH CARE 403 (I. Glenn Cohen ed., 2013). 
hazards along the environment/risk factors/illness pathway."92 Disease stigma is an example of one such health hazard inasmuch as it is independently correlated with poor health, ${ }^{93}$ which implies that both the absolute burdens of disease stigma and the distribution of those burdens-which communities are at highest risk of being stigmatized-are critical questions in thinking about just and humane health policies.

Another such determinant of population health, one that is closely related to stigma and discrimination, is trust, which is frequently operationalized in the epidemiologic literature as a component of social capital. ${ }^{94}$ Although space limitations preclude detailed discussions of the social capital-health connection, there is little dispute in this literature that trust is a key variable in determining health and its distribution in populations. ${ }^{95}$ The literature suggests that the significance of trust and social capital to health goes well beyond patient-provider relationships, but specifically impacts such relationships at least in part through the issue of medical mistrust.96 On this latter point, there is solid evidence that medical mistrust has a significant effect on outcomes of chronic disease

92 Hilary Graham, Social Determinants and their Unequal Distribution: Clarifying Policy Understandings, 82 MiLBANK Q. 101, 113 (2004).

93 See supra notes 65-70 and accompanying text.

94 Although the literature on this is immense, helpful starting points includethe following: Simon Szreter \& Michael Woolcock, Health by Association? Social Capital, Social Theory, and the Political Economy of Public Health, in HEALTH AND WeAlTH: STUDIES IN HISTORY AND PoLICY 376-415 (2004); Michael Woolcock, The Rise and Routinization of Social Capital: 1988-2008, 13 ANN. REV. POL. SCI. 469 (2010); Richard Wilkinson \& Kate Pickett, THE SPIRIT LEVEL: WHY GREATER EQUALITY MAKES SOCIETIES STRONGER 51-62 (2009); Ichiro Kawachi et al., Social Capital and Health: A Decade of Progress and Beyond, in Soclal CAPITAL AND HEALTH 1-26 (Ichiro Kawachi et al. eds.); Thomas Abel, Cultural Capital and Social Inequality in Health, 62 J. EPIDEMIOLOGY \& COMMUNITY HEALTH 1 (2008).

95 See Szreter and Woolcock, supra note 94.

96 See sources cited supra note 70. 
management. 97 There is also good evidence that medical mistrust is an enormous problem among communities suffering from disproportionate rates of chronic illness, ${ }^{98}$ including pain. ${ }^{99}$

Whether intended or not, the use of universal screening tools such as opioid contracts is likely to exacerbate this mistrust. The suspicion institutionalized in universal opioid contracts is therefore likely to have a disproportionate impact on those communities of pain sufferers that already suffer the most significant inequalities in (1) the diagnosis and treatment of pain; (2) social disadvantages that accumulate to produce more pain and worse health; (3) stigmatization and discrimination that are independently productive of poor health; and (4) medical mistrust that is inversely correlated with effective chronic disease management. The fact that all chronic pain sufferers that take opioids may be required to sign opioid contracts does not nullify the concern that such contracts will have a disproportionate impact on those most marginalized and vulnerable communities of pain sufferers. As the disparate impact doctrine shows, even policies that are universally applied can discriminate in unacceptable ways, and we believe that universal opioid contracts are a prime example of such a policy. The Supreme Court in Griggs emphasized that the issue of disparate impact is not a function of the motivations of the privileged, but is rather focused on the consequences of the policies and practices at issue on the marginalized. 100

97 See LaVeist et al., supra note 70; accord Wizdom Powell Hammond, Psychosocial Correlates of Medical Mistrust Among African American Men, 45 AM. J. CoMMUNITY PSYCHOLOGY 87 (2010).

98 See LaVeist et al., supra note 70; B. Ashleigh Guadagnolo et al., Medical Mistrust and Less Satisfaction With Health Care Among Native Americans Presenting for Cancer Treatment, 20 J. HEALTH CARE PoOR \& UNDERSERVED 210 (2009); L. Ebony Boulware et al., Race and Trust in the Health Care System, 118 PUB. HEALTH REP. 358 (2003).

99 Joseph O. Merrill et al., Mutual Mistrust in the Medical Care of Drug Users: The Keys to the 'Narc' Cabinet, 17 J. GEN. InTERNAL MED. 327 (2002).

100 Griggs v. Duke Power Co., 401 U.S. 424, 432 (1971). 
The concern that universal opioid contracts may have a disparate impact on those communities of chronic pain sufferers already experiencing the effects of cumulative disadvantages and social inequalities implicates key issues of social justice. One of the most sophisticated and persuasive expositions of the concept is found in Powers and Faden's work, in no small part because they integrate into their theory much of the epidemiologic evidence regarding the social determinants of health and the clustering of social disadvantages. Powers and Faden utilize this evidence base as a means of discerning which inequalities are of paramount ethical significance for public health policy. They conclude: "Which inequalities matter most? The answer we propose is that inequalities that contribute to systematic patterns of disadvantage are the ones that matter most."101 Under this rubric, policies and practices that exacerbate the densely-woven patterns of disadvantage which characterizes life for those on the tail of the social gradient are unjust and should not be tolerated.

Because stigma and mistrust are themselves key variables in these densely-woven patterns of disadvantage, policies and practices that raise a significant risk of intensifying these experiences should at least be strongly disfavored, and to the extent their intensification of stigma and mistrust can be rigorously documented, can fairly be labeled unjust. Powers and Faden's formulation of social justice is critical insofar as it stretches the ethical scope of justice beyond the distribution of primary goods. Thus, even where the use of universal opioid contracts does not preclude access to opioids for chronic pain sufferers that require them, their capacity for if not their likelihood of intensifying stigma and mistrust, and thereby worsening densely-woven patterns of disadvantage among alreadymarginalized communities, renders them ethically suspect.

Admittedly, the move to universal rather than ad hoc opioid contracts is rooted in an ostensible desire to ameliorate the stigmatization that so often accompanies the lived experiences of chronic pain. This goal is laudable, and 
our position here on the stigmatizing impact of universal opioid contracts is compatible with a belief that ad hoc opioid contracts pose significant concerns of selective application, discrimination, and stigmatization. Our conclusion is that there are profound reasons to doubt that moving to universal opioid contracts substantially ameliorates these concerns. Consequently, the appropriate policy question is not whether universal opioid contracts are preferable to ad hoc opioid contracts, but rather whether universal opioid contracts are truly preferable to no opioid contracts.

Disease stigma is pernicious. It is independently productive of poor health, can cause significant psychosocial suffering, and should not be tolerated in a just social order. Practices and policies that threaten to institutionalize such stigma should be avoided wherever possible. Moreover, there is incontrovertible evidence that millions of Americans suffer persistent, sometimes intense pain for which safe and effective treatments exist, including but not limited to opioids. Compounding this ethically intolerable situation, devastating inequities in the assessment and treatment of pain track virtually any social index that researchers have cared to examine. The conclusion that, as a society, the United States is and has been in the aggregate treating pain extremely poorly is unavoidable. We have grave doubts that it constitutes a humane response to this problem to institute policies and practices that pose a very real risk of stigmatizing the people whom we as a society are already failing.

\section{CONCLUSION}

In the summer of 2012, the Finance Committee of the U.S. Senate announced that it was initiating an investigation of the financial connections between certain major pharmaceutical manufacturers of prescription pain medications and experts in pain medicine, organizations that issue professional guidelines for the prescribing of such 
medications, and advocacy groups for patients with pain. ${ }^{102}$ The primary motivating factor for the investigation appears to be the prescription drug abuse epidemic alluded to in the introduction to this article and. more particularly, the suspicion that financial support of professional organizations in the field of pain medicine and their thought leaders has skewed practice guidelines, model policies, and even articles in peer-reviewed publications toward promotion of increased prescribing of opioid analgesics. The focus of the media accounts of this announcement was almost exclusively on those who acquire and misuse prescription pain medications and the injury and death that often follow from abuse of these medications. The plight of the many patients who receive and benefit significantly from these medications appeared as at best an afterthought and secondary consideration. For all of the reasons reviewed in this article, we now find ourselves in an increasingly hostile environment for chronic pain patients and the physicians who strive to treat them. More than ever, these patients are at risk that our society will revert to past prejudices against those who must rely on opioids for pain relief and functional improvement, and there is also a risk that our society will revert to a re-emergence of the opiophobia that plagued the health professions not so very long ago. The vulnerability of those afflicted with significant and persistent pain demands that medicine and society proceed with great caution in erecting barriers between conscientious physicians and their patients.

Finally, our criticisms of opioid contracts and the universal precautions approach ultimately do not depend on any substantive view of the propriety of opioid analgesics. That is to say, even if one maintains that the public health problem of prescription drug abuse sufficiently justifies curtailment of the use of opioid analgesics, it remains an open question whether the use of opioid contracts is

102 Press Release, U.S. Senate Comm. on Fin., Baucus, Grassley Seek Answers about Opioid Manufacturers' Ties to Medical Groups (May 8, 2012), available at http://www.finance.senate.gov/newsroom/ chairman/release/?id=021c94cd-b93e-4e4e-bcf4-7f4b9fae0047 (last visited Dec. 31,2013 ). 
ethically justified as a means to that end. Our position here is that regardless of one's perspective on the merits of the end, the universal use of opioid contracts is ethically dubious and should be scaled back if not abandoned entirely. 